\title{
Erratum to: Local and Global Mechanical Behavior and Microstructure of Ti6Al4V Parts Built Using Electron Beam Melting Technology
}

\author{
LEILA LADANI
}

DOI: $10.1007 / \mathrm{s} 11661-016-3402-1$

(c) The Minerals, Metals \& Materials Society and ASM International 2016

\section{Erratum to: METALLURGICAL AND MATERIALS TRANSACTIONS A, VOLUME 46A, SEPTEMBER 2015, pp. 3835-3841 DOI: 10.1007/s11661-015-2965-6}

FollOWING are corrections to the reference citations in the original article:

Page 3835, right column, first paragraph: Plastic deformation in Ti6Al4V material at room temperature was found to be caused by planar slip in the a grains, at quasi-static strain rates, while at high strain rates deformation twinning is also observed. ${ }^{[4]}$

Page 3835, right column, third paragraph: Study conducted by Antonysamy ${ }^{[5]}$ showed favored growth...

Page 3835, right column, fourth paragraph: The sentence "Change in mechanical properties relative to distance from build plate were evaluated in an experiment conducted at NIST" should be referenced to the following papers:

N. Hrabe and T. Quinn: Mater. Sci. Eng. A, 2013, vol. 573, pp. 264-70.

N. Hrabe and T. Quinn: Mater. Sci. Eng. A, 2013, vol. 573 , pp. 271-77.

Page 3836, left column, first paragraph: Contradictory to the previous studies which showed the preferential... The references cited in this sentence should be changed to:

N. Hrabe and T. Quinn: Mater. Sci. Eng. A, 2013, vol. 573 , pp. 264-70.

N. Hrabe and T. Quinn: Mater. Sci. Eng. A, 2013, vol. 573, pp. 271-77.

Page 3836, left column, first paragraph: Opposite to the findings of Ladani et al. ${ }^{[6]}$ which....

Page 3836, left column, second paragraph: Extensive research on EBM technique, quality of parts, types of defects, process parameter effects on defects, microstructure of material produced using this technique and

LEILA LADANI, Associate Professor, is with the Mechanical Engineering Department, University of Connecticut, Storrs, CT. Contact e-mail: lladani@engr.uconn.edu

The online version of the original article can be found under doi: 10.1007/s11661-015-2965-6.

Article published online March 14, 2016 mechanical behavior of parts over the last decade was conducted by Murr et al. ${ }^{[7-12]}$

Page 3836, left column, second paragraph: The idea that heat extraction can be utilized to form the desired microstructure was explored and to some extent realized by Oak Ridge National Lab recently as a structure was built in a carefully controlled manner in which the grain orientation was dictated and controlled at microscale. ${ }^{[13]}$

Page 3836, second column, first paragraph: Dog-bone specimens are fabricated based on the E8 M-04 ASME standard for subsize specimen using EBM system, Arcam ${ }^{\circledR}$ A2 manufactured by Arcam ${ }^{\circledR}$ AB in Sweden. ${ }^{[14]}$

Page 3837, left column, first paragraph: these specimens were close to the properties of Ti6A14V material fabricated using traditional techniques and also comparable to the other tests conducted on EBM postprocessed samples. ${ }^{[15-17]}$

Page 3837, left column, third paragraph: In uniaxial tensile/compressive testing, strain rate sensitivity (SRS) is measured as the change in observed strength as the applied strain rate is varied. SRS is often represented using the following equation: $:^{[18]}$

Page 3837, right column, first paragraph: Traditionally manufactured Ti6Al4V has shown strong positive SRS in literature. ${ }^{[4]}$

Page 3838, left column, second paragraph: A comparison between top and bottom sections of the top-built sample are is shown in Figure 4. Murr et al. have reported the average micro-indentation hardness ranges from 3.6 to $3.9 \mathrm{GPa}^{\left[{ }^{8]}\right.} \mathrm{Li}$ et al. have found that the average nanoindentation hardness values lie in between 4-5 GPa ${ }^{[19]}$ Qian et al. have found that nanoindentation hardness values are 10 to 30 pet higher than the micro-indentation hardness values for the same samples. ${ }^{[20]}$

Page 3838, right column, last paragraph: Perhaps the most interesting observation that also confirms the findings of the previous studies is that in side- and flat-built samples, the grains can be seen to have grown vertically perpendicular to the build orientation as seen in Figure 5(b). ${ }^{[5]}$

Page 3839, right column, first paragraph: ....are perpendicular to the loading direction, the dislocations may not have a long distance to travel. Additionally, existence of the a platelets limits the motion of dislocation along these platelets. ${ }^{[21]}$ 